\title{
La práctica profesional en la formación para la traducción de textos especializados: el caso de la traducción de textos socioeconómicos
}

\section{(Professional Practice in Training for the Translation of Specialized Texts: the Case of the Translation of Socioeconomic Texts)}

Mercedes EnRíquez ARANDA mmenriquez@uma.es Universidad de Málaga

Fecha de recepción: 26 de febrero de 2016

Fecha de aceptación: 15 de marzo de 2016

Resumen: La traducción de textos socioeconómicos supone un reto para la formación del traductor dada la amplitud de tipologías textuales y de competencias que engloba su concepto. Su alto grado de especialización convierte el proceso de enseñanza y aprendizaje de esta materia en un desafío tanto para discentes como para docentes dentro las estructuras propias de los diversos planes de estudio de los títulos universitarios de grado en España.

En este trabajo se aborda el diseño curricular de un módulo especializado en traducción socioeconómica dentro del Título de Grado en Traducción e Interpretación por la Universidad de Málaga. Se parte del contexto formativo general que ofrece el Título para describir en particular cómo se aborda una formación académica en este ámbito especialmente orientada a la práctica profesional.

Dadas las limitaciones temporales impuestas por el plan de estudios, urge aplicar en la enseñanza y aprendizaje de esta materia un enfoque profesional por una razón principal: se potencia la motivación de los alumnos por este campo de especialización que, en principio, se les presenta hostil en contenidos. Con la adecuada contextualización de las actividades traductoras formativas y la gradación de dificultad de las mismas, el alumno ubica su labor traductora en un todo laboral hacia el cual se le termina de encaminar en etapas posteriores de su formación.

Las sugerencias didácticas que se aportan son susceptibles de ser modificadas para su uso en contextos similares. 
Palabras clave: Práctica profesional de la traducción, Formación de traductores, Traducción de textos socioeconómicos, Competencia traductora, Diseño curricular

Abstract: Translating socioeconomic texts poses a challenge for translator training since it encompasses a wide range of text types and competences to be developed. Its high degree of specialization makes the teaching and learning of the subject a challenge for both learners and teachers within the frame of the various curricula of university degrees in Spain.

This work deals with the curriculum design of a specialized module in socioeconomic translation within the Degree in Translation and Interpreting at the University of Malaga. From the overall educational context provided in the Degree, the description of a practical training specially oriented towards the professional practice is addressed.

Given the time constraints imposed by the curriculum, it is advisable to implement in the teaching and learning of this subject a professional approach for one main reason: the motivation of students is enhanced by a field of specialization that in principle is regarded as hostile in contents. With a proper contextualization of the translator training activities and an adequate gradation of their difficulties, the student places the translating task within the translation market towards which (s)he is finally addressed at later stages of the training.

Teaching suggestions are provided in this work so that they can be modified for their use in similar contexts.

Key words: The professional practice of translation, Translator training, The translation of socioeconomic texts, Translation competence, Curriculum design

\section{INTRODUCCIÓN}

La propuesta de diseño curricular que se expone en el presente trabajo recoge los principales fundamentos teóricos y prácticos de los siguientes enfoques nacidos y desarrollados en el campo de la Didáctica de la traducción: el enfoque por objetivos de Delisle (1980 y 1993), el enfoque funcionalista de Vermeer (1998) y Nord (1991, 1997 y 2005), el enfoque textual de Neubert (1984 y 1992) y Hatim y Mason (1995 y 1997), el enfoque por tareas de Hurtado Albir (1999) y el enfoque constructivista y social de Kiraly (1995, 2000 y 2013). Estos dos últimos enfoques fueron aplicados a la enseñanza de la traducción de textos socioeconómicos por Li (2013) en tanto Socorro Trujillo (2013) hizo lo propio con el enfoque textual. 


\section{CONTEXTO FORMATIVO}

Con el fin de contextualizar la traducción de textos socioeconómicos dentro del Título Oficial de Grado en Traducción e Interpretación por la Universidad de Málaga, es necesario describir la formación de traductores en la Universidad de Málaga en relación con el contexto curricular del Título de Grado y las competencias profesionales que se persiguen en él.

\subsection{El Grado en Traducción e Interpretación por la Universidad de Málaga}

Desde su fundación en el año 1972 (BOE de 30 de septiembre de 1972), la Universidad de Málaga (UMA) ha experimentado un desarrollo notable tanto en oferta académica como en infraestructuras. ${ }^{1}$

En relación con la oferta académica, la UMA se ha convertido no solo en un gran dinamizador cultural de la ciudad, sino también en un considerable soporte del futuro tecnológico e investigador. La UMA constituye uno de los vértices del denominado "triángulo productivo" de la ciudad, formado además por el aeropuerto y el Parque Tecnológico de Andalucía. Este último está unido ya a la institución universitaria a través de un continuo flujo de ideas, profesionales de alta cualificación y tecnologías avanzadas. Es impulsora, junto a la Universidad de Sevilla, del Campus de Excelencia Internacional Andalucía $\mathrm{TECH},{ }^{2}$ especializado en las áreas de tecnologías de la producción, información y comunicaciones, y biotech.

Los Estudios de Traducción en la UMA son responsabilidad en la actualidad del Departamento de Traducción e Interpretación de la Facultad de Filosofía y Letras. No obstante, los Estudios de Traducción en la UMA no se adscribieron desde un principio al Departamento de Traducción e Interpretación. De hecho, como resume Calvo Encinas (2009: 221), el profesorado adscrito al Área de Estudios Árabes de la UMA fue quien tomó la iniciativa para la implantación de la carrera, por lo que, una vez esta entró en vigor, en el curso 1990-1991, los Estudios de Traducción e Interpretación se mantuvieron dentro del Departamento de Filología Griega y Estudios Árabes hasta la creación de su propio Departamento en 1998.

La UMA fue pionera en la implantación del Plan de estudios de la Licenciatura en Traducción e Interpretación en el marco de la Universidad española, con la implantación del Título de Licenciado en el curso académico 1990-1991. De hecho, los primeros Licenciados en Traducción e Interpretación de la Universidad española datan de 1994. En efecto, en el curso 1993-94 se graduó la primera promoción de Licenciados en Traducción e Interpretación en la UMA (por implantación del Título de

${ }^{1}$ Véase la página web de la UMA, http://www.uma.es, para acceder a la historia completa de su fundación y desarrollo a través de sus más de cuarenta años de existencia.

2 Véase http://www.andaluciatech.org para conocer más acerca de los Polos de Excelencia Docente Investigadora de este Campus de Excelencia Internacional. 
Licenciado en 1990-1991), en la Universidad de Granada y en la Universidad Autónoma de Barcelona (por realización de curso puente de antiguos Diplomados en Traducción e Interpretación) (Varios autores, 2008: 4).

Desde su implantación, los Estudios de Traducción e Interpretación en la UMA han experimentado un gran desarrollo tanto en número de alumnos (de 50 alumnos a principios de los años noventa hasta llegar a los 250 previstos para el curso académico 2015-2016), como en la estructuración de sus enseñanzas. Estos dos aspectos, unidos al desarrollo investigador, docente y profesional de los miembros del Departamento, llevan a confirmar su consolidación como oferta académica de calidad y competitiva a nivel nacional e internacional.

La Facultad de Filosofía y Letras, a través de su Departamento en Traducción e Interpretación, ofrece en la actualidad cuatro titulaciones relacionadas con los Estudios de Traducción: la Licenciatura en Traducción e Interpretación (Plan de estudios en el BOE de 20 de octubre de 1992 en extinción), el Grado en Traducción e Interpretación (ofertado desde el curso académico 2009-2010), el Máster Oficial en Traducción para el Mundo Editorial (en vigencia desde el curso académico 2008-2009) y el Programa de Doctorado Lingüística, Literatura y Traducción (implantado desde el curso académico 2013-2014). ${ }^{3}$

De acuerdo con la información contenida en la Memoria de Verificación del Título de Graduado/a en Traducción e Interpretación por la Universidad de Málaga (2008: 35-46) y teniendo igualmente presentes las modificaciones oficiales que se han hecho a ella hasta el presente, el Grado en Traducción e Interpretación por la UMA supone la extinción del Título de Licenciado en Traducción e Interpretación y se vincula a la rama de conocimiento de Arte y Humanidades. Su principal objetivo es formar a sus alumnos en las competencias necesarias para desempeñar las labores de traductor profesional generalista, traductor profesional especializado o intérprete de conferencias, en función del perfil de especialización que el alumno elija.

Las lenguas que se ofertan en el Título son: español (lengua materna A o L1), francés o inglés (lenguas B o L2), alemán, árabe, francés, griego, inglés o italiano (lenguas C o L3) y alemán, árabe, francés, griego, inglés o italiano (lenguas C2 o L4).

Sus 240 créditos ECTS de enseñanza presencial se reparten en cuatro años de acuerdo con la siguiente distribución en asignaturas:

3 Para más información, véanse las siguientes páginas web, respectivamente: http://www.uma.es/grado-en-traduccion-e-interpretacion/,

http://www.pop.uma.es/traduccioneinterpretacion/presentacion/index.php

http://www.uma.es/doctorado-llt/. 
formación básica (60 créditos), obligatorias (138 créditos) y optativas (42 créditos).

Se ofertan así 180 créditos por cada combinación lingüística principal y 60 créditos por cada segunda lengua extranjera, lo que hace un total de 720 créditos. Todos los créditos ofertados en la Formación Inicial Básica (60 créditos o un $25 \%)$ y 120 créditos de Formación Específica (50 \%) se corresponden con Módulos consensuados por las Universidades andaluzas que ofrecen el Título de Grado en Traducción e Interpretación (a saber, la Universidad de Granada, la Universidad Pablo de Olavide de Sevilla, la Universidad de Córdoba y la UMA), de manera que quedan a disposición libre de la UMA 60 créditos ECTS (25\%) de Formación Específica.

La estructura resultante, dividida por Módulos, Materias y Asignaturas, permite al alumno escoger entre tres itinerarios de formación específica en el cuarto curso, posibilidad única en Andalucía: traducción especializada, interpretación de conferencias y traducción generalista. Cada itinerario tiene una carga crediticia de 42 créditos optativos, que se suman a los 18 créditos obligatorios que componen el cuarto curso.

1.2. La traducción de textos socioeconómicos en el Plan de estudios del Grado en Traducción e Interpretación por la Universidad de Málaga

En el diseño curricular del Plan de estudios del Título de Grado en Traducción e Interpretación por la UMA se tuvieron muy en cuenta dos aspectos (Varios autores, 2008: 7-10).

Por un lado, se consideraron los perfiles profesionales definidos en el Libro Blanco del Título de Grado en Traducción e Interpretación (Muñoz Raya, 2004: 67-77), entre los que se encuentran, entre otros, el de traductor profesional especializado y el de lexicógrafo, terminólogo y gestor de proyectos lingüísticos.

Por otro lado, se contemplaron las salidas profesionales que han tenido los egresados en Traducción e Interpretación por la UMA desde la primera promoción de 1994, siendo una de ellas la de traductor especializado para el sector empresarial y económico y otra la de lexicógrafo o terminólogo.

A partir de estas informaciones, se diseñaron los itinerarios de formación específica anteriormente referenciados de tal suerte que se establecieron unos objetivos generales por cada itinerario en relación con las competencias generales y específicas del Título, amén de los objetivos formativos aplicados, técnicos y nocionales comunes para todos los alumnos del Grado en Traducción e Interpretación por la UMA (VV.AA., 2008: 19).

Los objetivos generales de acuerdo con el itinerario de formación en traducción especializada (VV.AA., 2008: 18-19) se relacionan con un 
traductor capaz de enfrentarse de forma eficiente a la traducción de textos especializados en, al menos, dos combinaciones lingüísticas (AB-BA y ACCA). Como resultados de aprendizaje, al finalizar este itinerario, el graduado será capaz de realizar, además de los objetivos planteados de forma general para todos los alumnos del Título de Grado en Traducción e Interpretación, la traducción de textos especializados dentro de uno o varios ámbitos especializados, distinguiéndose, por afinidad entre ellos, tres grandes ámbitos: científico-técnico, jurídico-económico y humanístico y audiovisual.

Las competencias básicas y generales atribuidas a partir el Título a la traducción en los ámbitos especializados jurídico y económico son, a día de hoy y tras la modificación oficial realizada en el curso académico 20122013, las siguientes:

\section{Competencias básicas}

\begin{tabular}{|c|c|}
\hline \multicolumn{2}{|r|}{ Competencias básicas } \\
\hline $\begin{array}{l}\text { B } \\
3\end{array}$ & $\begin{array}{l}\text { Que los estudiantes tengan la capacidad de reunir e interpretar datos } \\
\text { relevantes, normalmente dentro de su área de estudio, para emitir } \\
\text { juicios que incluyan una reflexión sobre temas relevantes de índole } \\
\text { social, científica o ética. }\end{array}$ \\
\hline $\begin{array}{l}B \\
5\end{array}$ & $\begin{array}{l}\text { Que los estudiantes hayan desarrollado aquellas habilidades de } \\
\text { aprendizaje necesarias para emprender estudios posteriores con un } \\
\text { alto grado de autonomía. }\end{array}$ \\
\hline \multicolumn{2}{|r|}{ Competencias generales } \\
\hline $\begin{array}{l}G \\
1\end{array}$ & $\begin{array}{l}\text { Capacidad para comunicarse de manera oral y escrita en la lengua } \\
\text { propia en niveles profesionales. }\end{array}$ \\
\hline $\begin{array}{l}\mathbf{G} \\
\mathbf{2}\end{array}$ & $\begin{array}{l}\text { Capacidad para comunicarse de manera oral y escrita en (al menos) } \\
\text { dos lenguas extranjeras a niveles profesionales. }\end{array}$ \\
\hline $\begin{array}{l}\text { G } \\
3\end{array}$ & $\begin{array}{l}\text { Capacidad para trabajar y aprender de forma individual o autónoma y } \\
\text { llevar a cabo una planificación del tiempo y una organización del } \\
\text { trabajo de una manera adecuada. }\end{array}$ \\
\hline $\begin{array}{l}\text { G } \\
4\end{array}$ & $\begin{array}{l}\text { Desarrollo de la capacidad para aplicar los conocimientos adquiridos } \\
\text { a la práctica. }\end{array}$ \\
\hline $\begin{array}{l}\text { G } \\
7\end{array}$ & $\begin{array}{l}\text { Desarrollo de la habilidad para resolver problemas y tomar las } \\
\text { decisiones apropiadas en cada contexto para realizar un trabajo de } \\
\text { calidad. }\end{array}$ \\
\hline $\begin{array}{l}\mathbf{G} \\
8\end{array}$ & $\begin{array}{l}\text { Adquisición de la capacidad para formular razonamientos críticos a } \\
\text { través de la argumentación y el diálogo. }\end{array}$ \\
\hline $\begin{array}{r}G \\
10\end{array}$ & $\begin{array}{l}\text { Adquisición de conocimientos analíticos y operativos de los nuevos } \\
\text { sistemas tecnológicos útiles para el diseño y gestión de proyectos en } \\
\text { tareas de traducción e interpretación. }\end{array}$ \\
\hline
\end{tabular}


G Adquisición de conocimientos de otras culturas y costumbres y 11 desarrollar las habilidades de interacción y mediación lingüística y cultural.

Tabla 1. Competencias básicas y generales del Título de Grado en Traducción e Interpretación por la Universidad de Málaga correspondientes a la traducción especializada jurídica y socioeconómica

La traducción de textos socioeconómicos, como se puede deducir, se incluye dentro de la traducción en los ámbitos especializados jurídico y económico. El módulo de Traducción e Interpretación acoge la materia Traducción Jurídica y Socioeconómica $B A-A B$, que a su vez se desglosa en tres asignaturas de seis créditos cada una: Traducción Jurídica $y$ Socioeconómica $B A-A B(I)$, Traducción Jurídica y Socioeconómica $B A-A B$ (II), Traducción Jurídica y Socioeconómica $B A-A B$ (III). La primera de ellas es obligatoria y se secuencia en el segundo semestre del tercer curso y las dos posteriores son optativas y se imparten en el primer y en el segundo semestre del cuarto curso, respectivamente. Las asignaturas optativas se ofertan junto a otras asignaturas de traducción en los ámbitos especializados científico y técnico y humanístico y audiovisual, tanto para el itinerario de traducción generalista como para el itinerario de traducción especializada.

Se entiende, por consiguiente, que todo alumno que curse el Grado en Traducción e Interpretación por la UMA tiene que desarrollar de manera obligatoria una serie de competencias específicamente relacionadas con la traducción de textos socioeconómicos. Si quiere adquirir competencias adicionales en este ámbito de especialización, cuenta, además, con la posibilidad de elegir doce créditos más en su itinerario de formación en el cuarto curso. Este diseño obedece a satisfacer las necesidades profesionales detectadas y expuestas en el Libro Blanco del Título de Grado en Traducción e Interpretación (Muñoz Raya, 2004: 67-77) y en el estudio sobre las salidas profesionales del egresado de la UMA anteriormente detalladas.

\section{DISEÑO CURRICULAR}

Dado que la asignatura Traducción Jurídica y Socioeconómica $B A-A B$ (I) es la única con carácter obligatorio de las tres asignaturas que contemplan la traducción de textos socioeconómicos, en ella se va a centrar la propuesta de diseño curricular que la autora de este trabajo ha ido implementado y desarrollando a lo largo de los cursos académicos 20112015 en el Grado en Traducción e Interpretación por la UMA y, en concreto, en la combinación lingüística inglés-español-inglés, siendo el inglés la lengua B o L2. 
Los datos descriptivos del diseño curricular de esta asignatura obedecen a la aplicación práctica de las normas y orientaciones recogidas en la Memoria de Verificación del Título de Graduado/a en Traducción e Interpretación por la Universidad de Málaga (Varios autores, 2008: 288293), el Plan de Ordenación Docente de la Universidad de Málaga. Curso académico 2015-2016 (Varios autores, 2015: 48-55) y documentos de circulación interna que la Oficina del Defensor Universitario hace llegar al profesorado de la UMA a través del Vicerrectorado de Ordenación Académica y Profesorado. ${ }^{4}$

\subsection{Descripción}

La asignatura se imparte en el Título de Grado en Traducción e Interpretación por la UMA, que se adscribe a la Facultad de Filosofía y Letras de la citada universidad. Su denominación oficial es Traducción jurídica y socioeconómica $B A-A B 1$ (inglés-español/español-inglés) (código $326)$. Es de tipo obligatoria y se incluye dentro de la materia 4 Traducción Jurídica y Socioeconómica $B A-A B$ y el módulo 5 de Traducción e Interpretación. Se secuencia en el segundo semestre del tercer curso del Grado. Su índice de experimentalidad es $2 .{ }^{5}$ Se imparte en español y en inglés en función de la direccionalidad de las traducciones (en español para la traducción directa y en inglés para la traducción inversa). El número de créditos totales de la asignatura es 6 , por lo que el alumno dedica 90 horas de trabajo autónomo y 45 horas presenciales, excluyendo las horas de evaluación establecidas en las convocatorias oficiales. Estas horas se distribuyen a razón de dos sesiones semanales de una hora y media cada una. Durante las siete primeras semanas de curso las dos sesiones se imparten en Grupo Grande y desde la octava semana hasta la decimoquinta y final semana una sesión corresponde al Grupo Grande y otra sesión al Grupo Reducido. ${ }^{6}$ El total de horas en Grupo Grande es de 33,3 y en Grupo Reducido es de 11,7 .

\footnotetext{
${ }^{4}$ Una versión reducida de esta propuesta curricular de los cursos anteriores se encuentra en el enlace a PROA (Programación docente) públicamente accesible en la siguiente dirección web: http://www.uma.es/grado-en-traduccion-e-interpretacion/.

${ }^{5}$ El índice de experimentalidad sirve para calcular la participación en número de horas por cada crédito en enseñanzas conducentes a la obtención de títulos de Graduado considerados de carácter experimental en la UMA. De acuerdo con el Plan de Ordenación Docente de la Universidad de Málaga (Varios autores, 2015: 7) "se estimará una participación de siete horas y treinta minutos por crédito en las asignaturas adscritas a áreas de conocimiento con índices de experimentalidad uno, dos o tres; y de diez horas por crédito en las asignaturas que estén adscritas a áreas de conocimiento con índices de experimentalidad cuatro, cinco o seis".

${ }^{6}$ Según el Plan de Ordenación Docente de la Universidad de Málaga (Varios autores, 2015: 9 10), el tamaño máximo de los Grupos Grandes se establece en setenta y dos alumnos computables y el de los Grupos Reducidos en treinta alumnos computables.
} 


\subsection{Recomendaciones y orientaciones}

El Plan de estudios no establece ningún prerrequisito. Sin embargo, es conveniente tener en cuenta las siguientes recomendaciones y orientaciones:

- Prerrequisitos esenciales: aunque no supongan incompatibilidades para cursar esta asignatura, es necesario que el alumno haya practicado la traducción directa e inversa en inglés y español. Debería haber aprovechado las asignaturas obligatorias del segundo curso Traducción general BA-AB 1 y 2 (inglés-español/español-inglés).

- Prerrequisitos aconsejables: el alumno podrá sacar más partido de la asignatura si cuenta con conocimientos básicos e instrumentales de informática, terminología y documentación que le facilitarán tanto el desarrollo de la asignatura como su adaptación al entorno real de la profesión. A tal fin, debería haber cursado y superado las asignaturas obligatorias Recursos informáticos aplicados a la traducción e interpretación (primer curso), Herramientas para la práctica de la traducción 1: terminología (segundo curso) y Herramientas para la práctica de la traducción 2: documentación (segundo curso). Igualmente, el conocimiento de las lenguas de trabajo (inglés y español) y de las culturas en las que se insertan le servirá para comprender y transmitir referencias culturales implícitas o explícitas en la traducción de textos jurídicos y socioeconómicos. Para ello, el alumno debería haber aprovechado las asignaturas obligatorias de primer curso Lengua y cultura $A$ aplicadas a la traducción e interpretación 1 y 2 y Lengua y cultura inglesas $B$ aplicadas a la traducción e interpretación 1 y 2, así como las asignaturas obligatorias de segundo curso Lengua y cultura $A$ aplicadas a la traducción e interpretación 3, Gramática normativa y Lengua y cultura inglesas $B$ aplicadas a la traducción e interpretación 3 y 4.

\subsection{Contexto}

A partir de su inserción en el Plan de estudios del Título de Grado en Traducción e Interpretación por la UMA, se considera que la función de esta asignatura es doble: afianzar métodos, técnicas y estrategias de traducción aplicados a textos jurídicos y socioeconómicos y aprehendidos en cursos precedentes, al tiempo que proponer por vez primera la práctica de la traducción de textos jurídicos y socioeconómicos desde y hacia la lengua inglesa (el español se considera la lengua materna A o L1).

Al tratarse de una asignatura obligatoria que se imparte en tercer curso, son muy importantes las asignaturas de otras materias impartidas en los cursos anteriores, ya que cimientan los conocimientos previos lingüísticos, culturales, teóricos e instrumentales necesarios para el alumno. 
Como asignatura obligatoria, los conceptos impartidos en ella son muy necesarios para el desarrollo profesional del alumno una vez finalizado el Grado en dos campos profesionales muy concretos y actuales: el de la traducción jurídica y el de la traducción socioeconómica.

Si se tiene en cuenta que el Grado tiene por objetivo principal la formación de profesionales en los campos de la traducción y de la interpretación en un mínimo de dos pares de lenguas, la primera lengua extranjera B (L2) y la segunda lengua extranjera C (L3), esta asignatura se puede definir como sustantiva.

El alumno matriculado en este Título ya comenzó su toma de decisiones en el primer curso. Su elección del inglés como primera lengua extranjera implicaba que quería adquirir una competencia traductora en esta lengua que le permitiera traducir textos especializados y no especializados en la combinación lingüística inglés-español-inglés. Esta competencia no es fácil de adquirir y no se puede alcanzar con una única asignatura. Las asignaturas instrumentales y sustantivas que hasta ahora había tratado el alumno le van a permitir aprovechar al máximo los nuevos conocimientos teóricos y prácticos que se comienzan a trabajar en esta asignatura y que le orientarán hacia los perfiles profesionales de traductor generalista 0 traductor especializado con especialización en textos jurídicos y socioeconómicos. Es muy importante que el alumno asimile bien estos nuevos conocimientos antes de adentrarse en el competitivo mundo laboral.

Esta asignatura se integra en el perfil del Título de Grado en Traducción e Interpretación según muestra la siguiente figura: 


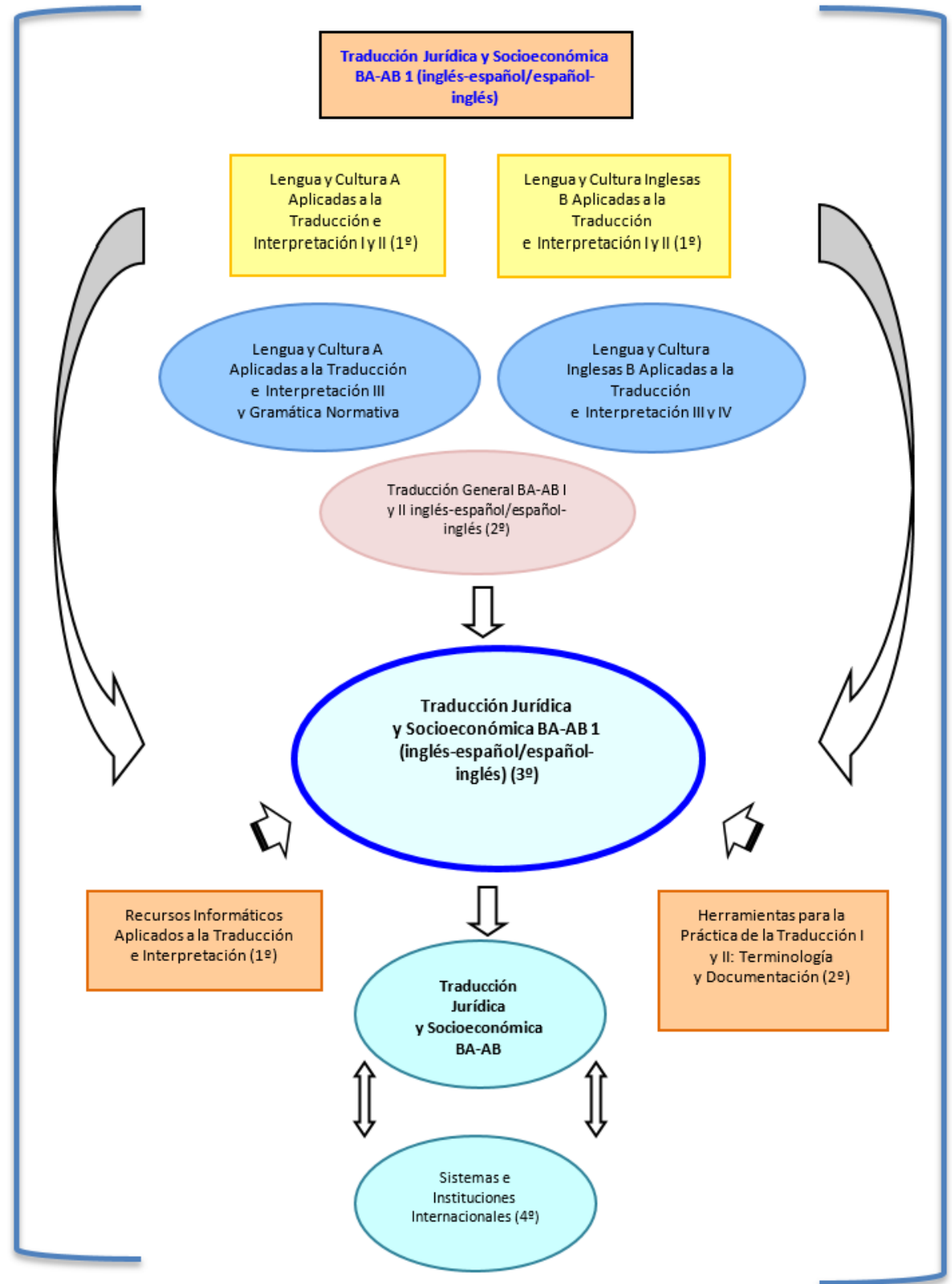

Figura 1. La Traducción Jurídica y Socioeconómica $B A-A B$ (I) en el perfil del Título de Grado en Traducción e Interpretación por la Universidad de Málaga 


\subsection{Competencias y resultados de aprendizaje}

Además de las competencias básicas y generales atribuidas a partir el Título a la traducción en los ámbitos especializados jurídico y económico, las siguientes son las competencias específicas que se desarrollan en la asignatura:

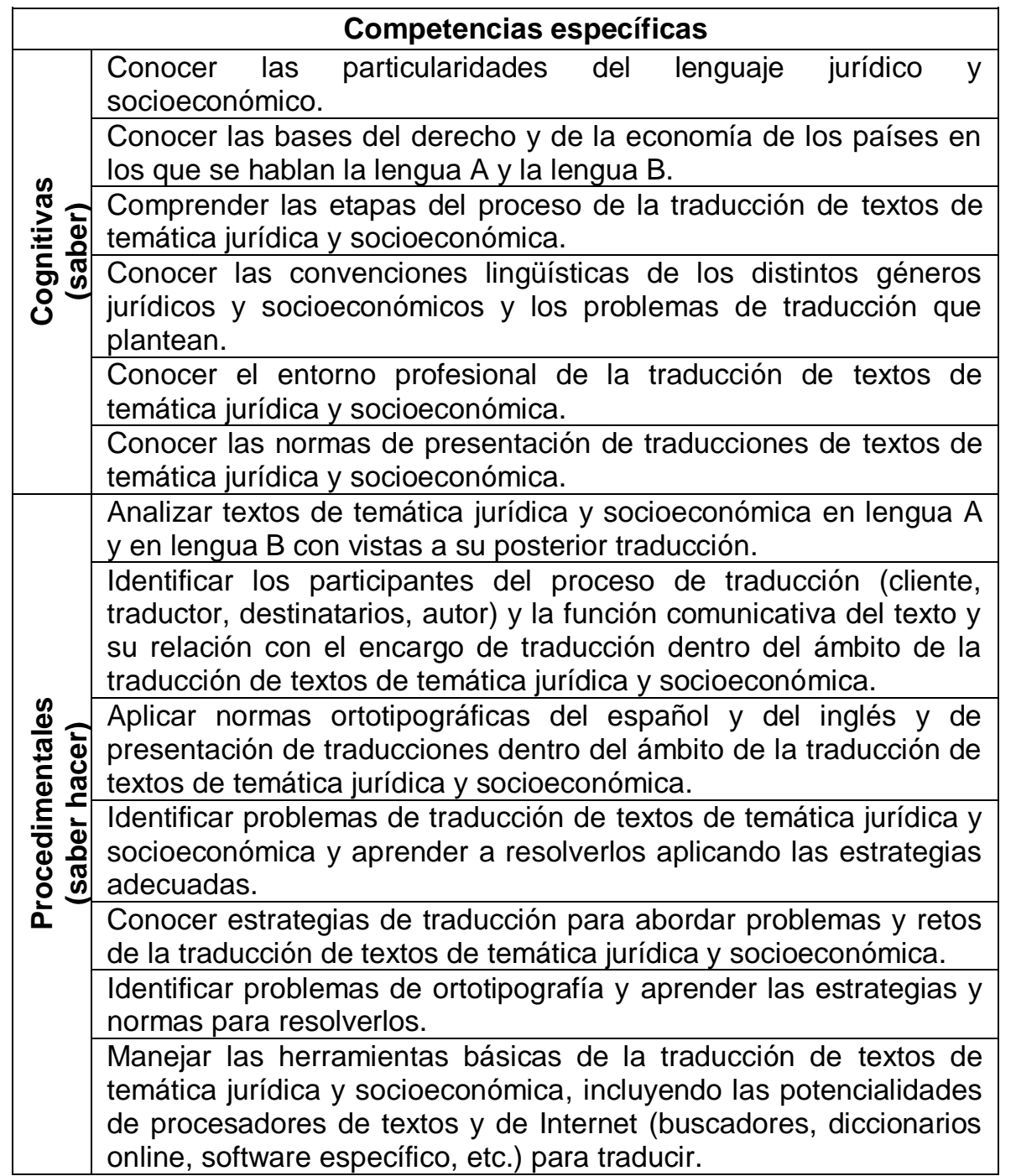




\begin{tabular}{|c|c|}
\hline & Utilizar textos paralelos. \\
\hline & Revisar y evaluar traducciones. \\
\hline & Ser capaz de trabajar en equipo. \\
\hline & $\begin{array}{l}\text { Utilizar las tecnologías de la información y la comunicación en los } \\
\text { procesos de enseñanza y aprendizaje. }\end{array}$ \\
\hline & $\begin{array}{l}\text { Estimular el interés por la traducción de textos de temática jurídica } \\
\text { y socioeconómica. }\end{array}$ \\
\hline & Comprender el papel del traductor como mediador intercultural. \\
\hline & Desarrollar razonamientos críticos y aprender con autonomía. \\
\hline & Reconocer la diversidad y la interculturalidad. \\
\hline $\bar{~}$ & $\begin{array}{l}\text { Identificar los aspectos derivados de la relación entre lenguaje y } \\
\text { género. }\end{array}$ \\
\hline & $\begin{array}{l}\text { Desarrollar habilidades para las relaciones interpersonales y la } \\
\text { mediación lingüística. }\end{array}$ \\
\hline
\end{tabular}

Tabla 2. Competencias específicas de la asignatura Traducción Jurídica y Socioeconómica $B A-A B(I)$ del Título de Grado en Traducción e Interpretación por la Universidad de Málaga

El objetivo general de la asignatura, por tanto, consiste en desarrollar la competencia traductora inglés-español-inglés de textos de temática jurídica y socioeconómica a partir de:

- La aplicación de bases teóricas, terminológicas e instrumentales (documentación y herramientas informáticas) en la traducción inglésespañol-inglés de textos de temática jurídica y socioeconómica.

- La comprensión de la traducción de textos de temática jurídica y socioeconómica como actividad profesional.

- La reflexión acerca del proceso de traducción desde una perspectiva lingüística y pragmática.

Al término de la asignatura, el estudiante será capaz de traducir diversos tipos de textos de temática jurídica y socioeconómica en diferentes grados, identificar diferentes tipos de documento y los problemas de traducción que plantea un determinado proyecto, analizar su capacidad para traducir cada encargo y producir una traducción de calidad aceptable en un tiempo razonable.

\subsection{Contenidos y cronograma}

Los contenidos de la asignatura se distribuyen en cuatro temas principales: la traducción jurídico-económica como ámbito de la traducción especializada, la traducción jurada: teoría y práctica, la traducción jurídica: introducción teórica y aplicaciones prácticas y la traducción socioeconómica: introducción teórica y aplicaciones prácticas. 
Estos contenidos se trabajan en los siguientes bloques temáticos:

Bloques temáticos

Bloque temático 1. Introducción a la asignatura (semana 1).

1. Introducción a la asignatura.

2. Conocimientos previos.

3. Metodología de enseñanza y aprendizaje.

Bloque temático 2. La traducción jurídico-económica como ámbito de la traducción especializada (semana 2).

1. Conceptos y dificultades de la traducción jurídica, jurada, judicial y socioeconómica.

2. El encargo de traducción.

3. Las fuentes de documentación.

Bloque temático 3. La traducción jurada: teoría y práctica (semanas $3-6)$.

1. La traducción jurada: concepto, tipos de encargo y direccionalidad.

2. La traducción jurada: normas de presentación.

3. Talleres prácticos de traducción.

Bloque temático 4. La traducción jurídica: introducción teórica y aplicaciones prácticas (semanas 7-10).

1. La traducción jurídica: caracterización general.

2. Talleres prácticos de traducción.

Bloque temático 5 . La traducción socioeconómica: introducción teórica y aplicaciones prácticas (semanas 11-14).

1. La traducción socioeconómica: caracterización general.

2. Talleres prácticos de traducción.

Bloque temático 6. Revisión de contenidos (semana 15).

1. Revisión de contenidos.

Tabla 3. Bloques temáticos de la asignatura Traducción Jurídica y Socioeconómica $B A-A B(I)$ del Título de Grado en Traducción e Interpretación por la Universidad de Málaga

Como se puede apreciar, la traducción de textos socioeconómicos es el último bloque temático de especialización que cuenta con igual número de horas de dedicación que los dos bloques temáticos anteriores, esto es, 12 horas de docencia presenciales.

\subsection{Actividades formativas}

La metodología docente persigue la participación activa del alumno como centro y responsable de su propio aprendizaje. La profesora tiene el papel de orientadora y facilitadora de los procesos de aprendizaje en torno a la traducción de textos de temática jurídica y socioeconómica. 
Se trabaja en clase de forma presencial, en gran grupo y en grupos reducidos según la secuenciación semanal. Las clases, expositivas y participativas, son:

- Sesiones teórico-prácticas introductorias a la teoría y práctica de la traducción de textos de temática jurídica y socioeconómica: lección magistral y prácticas en aulas de idiomas.

- Sesiones prácticas de traducción: prácticas en aulas de idiomas, exposiciones por parte del alumnado, discusión de textos y estudio/discusión de casos.

En ambos tipos de clases, se llevan a cabo traducciones directas e inversas de textos de temática jurídica y socioeconómica (inglés-españolinglés), ejercicios de crítica y comparación de traducciones, así como lectura, reflexión y crítica de bibliografía relacionada con la traducción de textos de temática jurídica y socioeconómica.

Antes de tratar cada uno de los ámbitos de especialización por separado, se hace necesaria una introducción conjunta a la traducción jurada, jurídica y socioeconómica. Se tratan aspectos tales como el ámbito profesional, el encargo de traducción, las fuentes documentales y las fichas y glosarios. $^{7}$

En el caso de la traducción de textos de temática socioeconómica, antes de proceder a la realización de encargos de traducción, se realiza una caracterización general de esta traducción en relación con las tipologías textuales y las características del discurso socioeconómico, siguiendo un método de carácter inductivo. ${ }^{8}$ Los encargos de traducción que se trabajan pertenecen a la traducción financiera (sector asegurador y sector de contabilidad y auditorías), a la traducción de marketing (planes de marketing y publicidad en páginas web) y a la traducción comercial (correspondencia comercial). De esta forma, dentro de las traducciones financieras, se reservan las traducciones para el sector bancario y de inversiones para la Traducción Jurídica y Socioeconómica BA-AB (II), así como las traducciones económicas y empresariales en su conjunto, tal como establece la Memoria de Verificación del Título de Graduado/a en Traducción e Interpretación por la Universidad de Málaga (Varios autores 2008: 290-292). Las traducciones se contextualizan con encargos de traducción que simulan situaciones reales dentro de la actividad traductora profesional. Se trabaja con un $70 \%$ de traducciones directas y un $30 \%$ de traducciones inversas, de acuerdo con las demandas actuales del mercado. Las traducciones inversas se secuencian en tiempo tras las traducciones

7 Cf. el anexo 4.1. "La traducción jurídico-económica como ámbito de la traducción especializada".

8 Cf. el anexo 4.2. "La traducción socioeconómica: introducción teórica y aplicaciones prácticas". 
directas y el número de palabras de cada traducción varía en función del grado de dificultad del texto original en relación con el encargo de traducción así como de la necesidad de incluir otros elementos accesorios a la traducción como, por ejemplo, la maquetación de tablas, imágenes o gráficos, tan propia de este ámbito de especialización traductora.

El trabajo que desarrolla el alumno es tanto individual como en equipo. La asistencia y la participación activa del alumno son muy recomendables para el buen hacer de la asignatura, al tiempo que son consideradas de cara a la evaluación. Las lenguas de trabajo son el inglés y el español, en función de la direccionalidad de la traducción.

Además, el alumno trabaja de forma autónoma no presencial. Las actividades que desarrolla son: realización de glosarios (un glosario electrónico en el Campus Virtual correspondiente a términos del ámbito jurídico y otro correspondiente a términos del ámbito socioeconómico), participación en foros de debate (dentro también del Campus virtual, uno correspondiente a la formación continua y otro correspondiente a la profesión del traductor especializado en ambos ámbitos de especialización así como en la traducción jurada) y estudio personal relacionado con la preparación de las actividades cuyos resultados se ponen en común en las clases presenciales.

\subsection{Procedimientos de evaluación}

La evaluación inicial del alumno se realiza a través de las actividades introductorias a la propia asignatura y a cada uno de los ámbitos de la traducción especializada que se tratan en ella.

Los procedimientos de evaluación sumativa en relación con la consecución de los objetivos de la asignatura quedan reflejados en la siguiente tabla:

Procedimientos de evaluación

\begin{tabular}{|c|c|c|}
\hline \multicolumn{3}{|c|}{ Procedimientos de evaluación } \\
\hline \multicolumn{3}{|c|}{ Evaluación continua en primera convocatoria ordinaria } \\
\hline Componentes & Criterios de evaluación & Porcentaje \\
\hline $\begin{array}{l}\text { Pruebas escritas } \\
\text { parciales } \\
\text { individuales }\end{array}$ & \multirow{2}{*}{$\begin{array}{l}\text { - Calidad de la traducción (proceso y } \\
\text { producto) de acuerdo con el baremo } \\
\text { de corrección de traducciones. } \\
\text { - Reflexión crítica y documentada } \\
\text { sobre cuestiones adicionales acerca } \\
\text { de la traducción de textos de temática }\end{array}$} & $80 \%$ \\
\hline $\begin{array}{l}\text { Traducción jurada y } \\
\text { jurídica }\end{array}$ & & $40 \%$ \\
\hline
\end{tabular}




\begin{tabular}{|c|c|c|}
\hline $\begin{array}{l}\text { Traducción } \\
\text { socioeconómica }\end{array}$ & $\begin{array}{l}\text { jurídica y/o socioeconómica que se } \\
\text { planteen en la prueba. }\end{array}$ & $40 \%$ \\
\hline $\begin{array}{lr}\text { Participación } & \text { en } \\
\text { actividades } & \text { de } \\
\text { clase: encargos de } \\
\text { traducción y } & \text { otras } \\
\text { actividades } & \text { en } \\
\text { grupos } & \text { y/o } \\
\text { individuales } & \end{array}$ & $\begin{array}{l}\text { - Adecuación del contenido y de la } \\
\text { presentación de los encargos de } \\
\text { traducción a los criterios de } \\
\text { evaluación que se especifiquen. } \\
\text { - Rendimiento satisfactorio en las } \\
\text { actividades propuestas para su } \\
\text { desarrollo en las sesiones } \\
\text { presenciales. }\end{array}$ & $10 \%$ \\
\hline $\begin{array}{lr}\text { Participación } & \text { en } \\
\text { actividades } & \text { del } \\
\text { Campus Virtual en } & \text { en } \\
\text { grupos } & \text { y/o } \\
\text { individuales } & \end{array}$ & $\begin{array}{l}\text { - Rendimiento satisfactorio en las } \\
\text { actividades propuestas para su } \\
\text { desarrollo en las sesiones virtuales. }\end{array}$ & $10 \%$ \\
\hline \multicolumn{3}{|c|}{$\begin{array}{l}\text { - Las pruebas parciales son unas pruebas escritas que consisten cada una } \\
\text { en la traducción (jurada) de uno o varios textos o fragmentos de textos de } \\
\text { temática jurídica y/o socioeconómica, de características similares a los } \\
\text { realizados en clase. Además, se tiene que responder a una serie de } \\
\text { cuestiones relativas a los problemas de traducción encontrados en el } \\
\text { desarrollo de la prueba y/o a cuestiones teórico-prácticas más generales } \\
\text { tratadas en el temario de la asignatura. Para la realización de las pruebas } \\
\text { parciales el alumno puede utilizar todas las obras de referencia y toda la } \\
\text { documentación que considere necesarias, tanto en papel como } \\
\text { electrónicas. Puede utilizar asimismo Internet. El tiempo total asignado a } \\
\text { cada prueba no excede de una hora y treinta minutos. } \\
\text { - Para que computen todos los porcentajes, es necesario obtener una nota } \\
\text { mínima de } 4 \text { sobre } 10 \text { en cada una de las pruebas escritas parciales } \\
\text { individuales (traducción jurada y jurídica y traducción socioeconómica). } \\
\text { - En el momento de la publicación de las calificaciones finales se indica la } \\
\text { fecha de revisión. }\end{array}$} \\
\hline \multicolumn{3}{|c|}{$\begin{array}{c}\text { Evaluación final en primera y en segunda convocatoria ordinaria } \\
\text { y en convocatorias extraordinarias }\end{array}$} \\
\hline Componentes & Criterios de evaluación & Porcentaje \\
\hline $\begin{array}{l}\text { Prueba escrita final } \\
\text { individual }\end{array}$ & $\begin{array}{l}\text { - Calidad de la traducción (proceso y } \\
\text { producto) de acuerdo con el baremo } \\
\text { de corrección de traducciones. } \\
\text { - Reflexión crítica y documentada }\end{array}$ & $100 \%$ \\
\hline
\end{tabular}

${ }^{9}$ Cf. el anexo 4.3. "Baremos de corrección de traducciones directas/inversas". 


\begin{tabular}{|l|l|l|}
\hline & $\begin{array}{l}\text { sobre cuestiones adicionales acerca } \\
\text { de la traducción de textos de temática } \\
\text { jurídica y/o socioeconómica que se } \\
\text { planteen en la prueba. }\end{array}$ \\
\hline - La prueba escrita final individual es semejante a las pruebas. El tiempo \\
total asignado a la prueba no excede de las tres horas. \\
- En el momento de la publicación de las calificaciones finales se indica la \\
fecha de revisión. \\
Tabla 4. Procedimientos de evaluación de la asignatura Traducción Jurídica y \\
Socioeconómica BA-AB (I) del Título de Grado en Traducción e \\
Interpretación por la Universidad de Málaga
\end{tabular}

Todo alumno que, o bien no pueda seguir la evaluación continua en primera convocatoria ordinaria, por un motivo debidamente justificado por escrito, o bien no logre superarla, ha de seguir la evaluación final en la primera y/o en la segunda convocatoria ordinaria y/o en las convocatorias extraordinarias sucesivas a las que tenga derecho, y hacer en estas convocatorias una única prueba escrita final individual del temario completo de la asignatura en las fechas oficiales establecidas por la Facultad de Filosofía y Letras de la Universidad de Málaga.

La evaluación continua y la evaluación final en la primera convocatoria ordinaria son excluyentes entre sí.

No se guardan las calificaciones de una convocatoria a otra.

El alumno a tiempo parcial y el deportista universitario de alto nivel, siempre que acrediten su condición por escrito, pueden realizar la evaluación continua en primera convocatoria ordinaria de forma que el porcentaje de valoración del componente "Participación en actividades de clase" será evaluado con pruebas complementarias.

Los alumnos de programas de movilidad trabajan en igualdad de condiciones. Se tienen en cuenta, no obstante, sus lenguas maternas para la valoración de su participación en la asignatura, de las actividades que realicen y de las pruebas, así como para la formación de grupos de trabajo que fomenten el trabajo colaborativo entre alumnos con diferentes lenguas maternas.

La detección del plagio y del uso de herramientas de traducción automática en cualquiera de las actividades evaluables programadas para esta asignatura anula dicha prueba, lo que supone una calificación de 0 puntos en la misma. La UMA ha incorporado recientemente la herramienta informática para la detección de plagio Ephorus en el Campus Virtual.

Al alumno se le proporciona desde la primera sesión de clase un documento que contiene las normas y criterios de evaluación específicos de 
cada uno de los componentes de la evaluación continua y final. ${ }^{10}$ En este documento se menciona la importancia de la participación del alumno en las actividades que se proponen en la asignatura, de manera que se tiene en cuenta como parte de su evaluación formativa, valorándola positivamente sobre la nota final del alumno. Se realiza, por consiguiente, un proceso de atención individualizada a la evaluación de cada alumno.

\subsection{Bibliografía y otros recursos}

El Campus Virtual, ${ }^{11}$ un entorno de virtual de enseñanza-aprendizaje desarrollado a partir de Moodle por el Servicio de Enseñanza Virtual de la Universidad de Málaga, es un medio básico para el desarrollo de la asignatura. En esta plataforma se cuelga el material de la asignatura: el programa, la guía docente y la secuenciación de contenidos, las unidades didácticas, las tareas y cualesquiera otros documentos metodológicos necesarios. Asimismo, se utiliza para informar a los alumnos de cualquier cambio relativo a los calendarios, los horarios, las tutorías, el programa, la secuenciación, las actividades, etc.

En clase y/o a través del Campus Virtual de la asignatura se proporciona material específico y bibliografía complementaria a la que se ofrece de manera general. En el campo de especialización de la traducción de textos de temática socioeconómica se aconsejan las siguientes fuentes de documentación orientativas:

\section{Bibliografía sobre la traducción de textos de temática socioeconómica}

\section{Diccionarios especializados:}

1. Alcaraz Varó, E. (1999): Diccionario de términos de marketing, publicidad y medios de comunicación inglés-español/español-inglés, Barcelona, Ariel.

2. Alcaraz Varó, E. y B. Hughes (2007): Diccionario de comercio internacional: importación y exportación. Inglés-español/español-inglés, Barcelona, Ariel.

3. Alcaraz Varó, E., B. Hughes y J. Mateo Martínez (2012): Diccionario de términos económicos, financieros y comerciales inglésespañol/español-inglés, Barcelona, Ariel.

4. Lozano Irueste, J.M. (2001): Diccionario bilingüe de economía y empresa (Español-Inglés/English-Spanish), Madrid, Pirámide.

5. Routledge Spanish Dictionary of Business, Commerce and Finance:

${ }^{10}$ Cf. el anexo 4.4. "Normas y criterios de evaluación".

11 Véase

http://campusvirtual.cv.uma.es/index.php?option=com_content\&task=view\&id=44\&ltemid=80. 
Spanish-English, English-Spanish (1998) Londres, Routledge (CDROM). 6. Sanz Santolaria, C.J. (2002): Diccionario económico, contable, comercial y financiero, Barcelona, Gestión 2000.

Recursos electrónicos de la Biblioteca de la Universidad de Málaga:

1. Collin, S.M.H. (2006): Dictionary of Business, Londres, A\&C Black.

2. Collin, S.M.H. (2006): Dictionary of Economics, Londres, A\&C Black.

3. Collin, S.M.H. (2007): Dictionary of Accounting, Londres, A\&C Black.

4. Hinkelman, E.G. (2002): Dictionary of International Trade. Novato (CA), orld Trade Press.

5. Yadin, D. L. (2002): The International Dictionary of Marketing. Londres, Kogan Page.

Revistas especializadas:

En la Biblioteca de la Universidad de Málaga, entre otras:

1. Academy of Marketing Studies Journal. Cullowhee, N.C.: Allied Academies.

2. Economic and Labour Market Review. Londres: Office for National Statistics.

Base de datos académica:

Business Source Complete. Ipswich, MA: EBSCO Publishing (Recurso electrónico).

Tabla 5. Bibliografía sobre la traducción de textos de temática socioeconómica de la asignatura Traducción Jurídica y Socioeconómica BA-AB (I) del Título de Grado en Traducción e Interpretación por la Universidad de Málaga

\section{PRÁCTICA PROFESIONAL}

La adquisición de la competencia traductora en el ámbito de los textos socioeconómicos dentro del Título Oficial de Grado en Traducción e Interpretación por la Universidad de Málaga se fundamenta, por tanto, en la asignatura Traducción Jurídica y Socioeconómica $B A-A B$ (I) y se complementa, con carácter optativo, en las dos asignaturas homónimas posteriores. Entre el módulo dedicado a la traducción de textos socioeconómicos de esta asignatura (12 horas) y las horas que se pueden dedicar en las asignaturas posteriores (en torno a las 45 horas) las horas presenciales que se destinan al proceso de enseñanza y aprendizaje de un campo de especialización tan amplio y tan complejo como el de la traducción de textos socioeconómicos asciende a 57 horas.

Dadas las limitaciones temporales impuestas por el Plan de estudios, urge aplicar en la asignatura obligatoria de base un enfoque profesional por una razón principal: se potencia de esta manera la motivación de los alumnos por este campo de especialización que, en principio, se les presenta hostil en contenidos (no hay que olvidar que la mayor parte de los alumnos acceden al Grado desde un Bachillerato de Humanidades) y 
aproximación traductora (la imbricación de las competencias instrumentales específicas con un campo de especialización tan concreto ya es una realidad). Con la adecuada contextualización de los encargos de traducción y la gradación de dificultad de los mismos, el alumno ubica su labor traductora en un todo laboral hacia el cual se le termina de encaminar en las asignaturas posteriores y se le afianza en la asignatura obligatoria de último curso Prácticas Externas.

En esta asignatura, durante el curso 2014-2015 se ofertaron 201 plazas para los 151 alumnos matriculados en febrero de 2015. De estas plazas, 19 fueron plazas para prácticas en empresas cuyas tareas se relacionaban con la traducción de textos socioeconómicos: un 9,5\%. Las tareas principales fueron, por este orden, tareas de marketing, correspondencia comercial, traducción de textos empresariales y participación en proyectos de traducción financiera. El predominio de la lengua inglesa como lengua B o L2 fue claro por encima del resto de lenguas solicitadas (alemán y francés).

Los alumnos, al igual que la profesora, son conscientes de las limitaciones del Plan de estudios en cuanto al tiempo de formación establecido para una especialización traductora tan compleja, pero el diseño curricular de la asignatura, asentado en una formación académica para la práctica profesional, permite descargar la fundamentación conceptual y teórica a favor de un modelo de enseñanza-aprendizaje inspirado en el mundo laboral.

\title{
4. ANEXOS \\ 4.1. La traducción jurídico-económica como ámbito de la traducción especializada
}

\author{
1. Ámbito profesional \\ Actividades: \\ 1. CUESTIONARIO INICIAL: \\ 1.1. ¿Qué entiendes por traducción de textos jurídicos, judiciales y \\ socioeconómicos? \\ 1.2. ¿Qué es la traducción jurada? \\ 1.3. ¿Qué mercado laboral consideras que existe para estos tipos de \\ traducciones? \\ 1.4. ¿Qué competencias crees que debe tener el traductor de estos tipos de \\ textos? \\ 1.5. ¿Qué grado de importancia concedes a esta asignatura para tu \\ formación? \\ 1.6. A nivel personal, ¿te interesa este tipo de traducción? \\ 2. TAREAS:
}


2.1. ¿Conoces asociaciones profesionales de traductores? ¿Cuáles? Realiza una búsqueda completa y confecciona una lista con las asociaciones españolas más importantes donde detalles sus actividades y su forma de contacto. Haz lo mismo con las asociaciones internacionales más destacadas. ¿Existe alguna de ellas especialmente orientada a la traducción de textos jurídicos, judiciales y/o socioeconómicos? ¿Y a la traducción jurada?

2.2. ¿Conoces la Norma UNE EN-15038:2006 Servicios de traducción. Requisitos para la prestación del servicio? Haz una breve descripción de sus objetivos y valora su utilidad para el ejercicio profesional de la traducción jurada y de la traducción de textos jurídicos, judiciales y socioeconómicos. Realiza la misma tarea en relación con la Norma UNE EN-ISO 9001: 2008 Sistema de gestión de calidad (próximamente UNE-ENISO 9001: 2015).

3. PREPARACIÓN A LA LECTURA:

3.1. ¿En/Para qué tipo de empresas crees que puede trabajar el traductor de textos jurídicos, judiciales y socioeconómicos? ¿Y el intérprete jurado?

3.2. ¿Cuáles crees que son sus condiciones de trabajo: tareas, contratos, remuneración...?

4. LECTURA DE LOS EJEMPLOS: http://www.iribarren-uriz.com/index.php/es/ y http://www.asesoriainternacional.es/

5. PREGUNTAS:

5.1. ¿De qué tipo de empresas se trata?

5.2. ¿Qué papel(es) desempeña el traductor en estas empresas?

5.3. ¿Tiene el traductor alguna relación con los textos jurídicos, judiciales y socioeconómicos? ¿Y con la traducción jurada?

6. TAREA:

6.1. Busca otros tipos de empresas en las que también se incluyan servicios de traducción de textos jurídicos, judiciales y socioeconómicos, así como servicios de traducción jurada. Haz una lista donde detalles sus datos principales, sus actividades y su forma de contacto.

\section{El encargo de traducción}

\section{Actividades:}

LECTURA DE LOS TEXTOS:

- Texto 1: Barclays web (inglés).

- Texto 2: Change of Name Deed (inglés).

- Texto 3: Contrato de Acuerdo de Colaboración de Servicio (español).

- Texto 4: Demanda (español).

2. PREGUNTAS:

2.1. ¿Podrías decir a qué campo temático se adscribe cada texto? ¿Por qué? 
2.2. Define someramente las características extratextuales e intratextuales de cada texto.

2.3. ¿Consideras estos textos susceptibles de encargos de traducción?

2.4. ¿A qué tipo de traducción se adscribirían?

2.5. Reflexiona acerca de las dificultades que supondrían las traducciones de estos textos en relación con los siguientes encargos de traducción y las características extratextuales e intratextuales de cada uno que antes has detallado:

- Texto 1: Barclays quiere extender su programa de captación de clientes a los residentes españoles en el Reino Unido. A tal fin, te encarga la traducción al español de la publicidad en línea de algunos de sus productos.

- Texto 2: Una ciudadana británica residente en España desea matricular a su hijo en un instituto público. Le solicitan las traducciones juradas al español de varios documentos, entre los que se encuentra el siguiente.

- Texto 3: A fin de que el documento sea comprensible en el país donde se va a ejecutar, te encargan su traducción al inglés.

- Texto 4: Te solicitan la traducción al inglés del siguiente texto para su comprensión por las partes demandadas, de nacionalidad estadounidense.

3. TAREA:

3.1. Supón que aceptas los encargos como traductor autónomo. ¿Qué pasos deberías seguir? Examina los documentos "Modelo de presupuesto" (documento 1) y "Modelo de factura" (documento 2) y elabora un presupuesto para las cuatro traducciones. ${ }^{12}$

\section{Las fuentes documentales}

\section{Actividades:}

1. PREPARACIÓN A LA TAREA:

1.1. Volviendo a las competencias que el traductor jurado y el traductor de textos jurídicos, judiciales y socioeconómicos debe tener: ¿qué lugar crees que ocupa entre ellas la competencia documental? Razona tu respuesta.

1.2. ¿Qué tipos de fuentes documentales crees que son útiles para la especialización en traducción de textos jurídicos, judiciales y socioeconómicos? ¿Y para la traducción jurada? Razona tu respuesta.

2. LECTURA DE LA BIBLIOGRAFÍA Y ANÁLISIS DE LAS FUENTES DOCUMENTALES SEGÚN SU UTILIDAD (ESPECIALIZACIÓN Y DIRECCIONALIDAD).

3. TAREAS:

3.1. Vuelve a los textos tratados en el apartado "2. El encargo de traducción" y recuerda las características intratextuales y los elementos extratextuales

${ }^{12}$ Los modelos de presupuesto y de factura que se proponen se pueden elaborar a partir de las plantillas que ofrecen algunos paquetes informáticos o bien dejar al alumno que elabore sus propios modelos. 
que habías tenido en cuenta para valorar las dificultades de los encargos de traducción proporcionados:

3.1.1. Estudia ahora las fuentes documentales que utilizarías para solventar las posibles dificultades de traducción que te podrías encontrar a partir del análisis que hiciste previamente.

3.1.2. Aporta ejemplos concretos para diferentes dificultades intratextuales y extratextuales que necesiten documentación (dificultad, fuente, solución).

3.1.3. Además de las fuentes aportadas en este apartado, ¿te ha hecho falta alguna más? ¿Cuál? ¿Por qué?

3.2. Revisa los recursos en línea que se presentan en la bibliografía y reflexiona sobre su conveniencia y fiabilidad.

\section{Fichas y glosarios}

\section{Actividades:}

1. PREPARACIÓN A LA TAREA:

1.1. ¿Sabrías explicar la diferencia entre Glosario terminológico y Ficha terminológica?

1.2. ¿Qué utilidad consideras que tienen estas herramientas documentales para el traductor en general? ¿Y para el traductor de textos jurídicos, judiciales y socioeconómicos en particular?

1.3. ¿Qué otros recursos terminológicos están a disposición del traductor de textos especializados?

2. REVISIÓN DEL "MODELO DE FICHA TERMINOLÓGICA".13

2.1. Compara este modelo con el que ofrece el DAMT Multilingual Dictionary. Analytical Dictionary of Globalization and Labour (http://zedamt.herokuapp.com/index).

3. TAREA:

3.1. De los textos 1 y 2 tratados en el apartado "2. El encargo de traducción", selecciona un término en inglés sobre el que realizar una ficha terminológica siguiendo el modelo propuesto.

\footnotetext{
${ }^{13} \mathrm{El}$ modelo de ficha terminológica que se propone contiene los siguientes campos: entrada inglés, entrada español, categoría inglés, categoría español, campo de uso específico, campos de uso asociados, definición en inglés y fuente, definición en español y fuente, contexto en inglés y fuente, contexto en español y fuente, comentarios. Para más información sobre actividades relacionadas con glosarios en este campo de especialización concreto, véase Gallego Hernández, Daniel, "Elaboración de glosarios económicos con fines docentes: aproximación metodológica basada en corpus y explotación terminológica en el aula de traducción." En: InTRAlinea: Translation \& lexicography. Disponible en línea en: http://www.intralinea.org/specials/article/elaboracion_de_glosarios_economicos_con_fines_doc entes [Fecha de consulta: 26 de febrero de 2016]
} 
3.2. De los textos 3 y 4 tratados en el apartado "2. El encargo de traducción", selecciona un término en español sobre el que realizar una ficha terminológica siguiendo el modelo propuesto.

3.3. Valora algunos glosarios en línea citados en el apartado "3. Las fuentes documentales" y reflexiona sobre su conveniencia y fiabilidad para el traductor.

4.2. La traducción socioeconómica: introducción teórica y aplicaciones prácticas

\section{Tipología textual}

\section{Actividades:}

1. PREPARACIÓN A LA LECTURA:

1.1. Revisa la lista de empresas que ofrecían servicios de traducción de textos jurídicos, judiciales y socioeconómicos, así como servicios de traducción jurada (tarea 6.1. del apartado "1. Ámbito profesional" de la unidad "La traducción jurídico-económica como ámbito de la traducción especializada").

1.2. ¿Qué tipología de textos socioeconómicos puedes deducir a partir de la información que ofrecen las empresas consultadas?

2. LECTURA:

2.1. Lee con detenimiento el texto "La traducción de textos socioeconómicos según 1GlobalTranslators" (http://www.1globaltranslators.com/).

3. PREGUNTAS:

3.1. ¿Coincide la tipología textual con la que habías deducido anteriormente?

3.2. ¿Cómo clasificarías esta tipología textual según el grado de especialización? Ayúdate de la definición que encuentres de los siguientes términos en fuentes documentales especializadas: economía, finanzas, marketing, comercio, empresa.

3.3. ¿Cómo crees que afecta la direccionalidad en traducción a la tipología textual?

\section{El discurso socioeconómico: características}

Actividades:

1. TAREAS:

1.1. ¿Qué características intratextuales definen al discurso socioeconómico? (recuerda las que ya discutiste en la pregunta 2.2. del apartado "2. El encargo de traducción" de la unidad "La traducción jurídico-económica como ámbito de la traducción especializada").

1.2. ¿Cuáles serían los elementos extratextuales que se deberían tener en cuenta para su traducción? (recuerda los que ya discutiste en la pregunta 
2.2. del apartado "2. El encargo de traducción" de la unidad "La traducción jurídico-económica como ámbito de la traducción especializada").

2. LECTURA:

2.1. Lee con detenimiento el texto "The future of jobs" (http://www.economist.com/news/briefing/21594264-previous-technologicalinnovation-has-always-delivered-more-long-run-employment-not-less).

3. PREGUNTAS:

3.1. Vuelve a responder a las preguntas de la actividad 1 ejemplificando con el texto leído en relación con el siguiente encargo de traducción:

La situación laboral a nivel mundial es objeto de un estudio detallado en la edición electrónica del diario español de economía y finanzas Expansión. Te solicitan la traducción al español de los artículos más recientes en torno al tema, entre los cuales se halla el presente.

\subsection{Baremos de corrección de traducciones directas/inversas}

- La puntuación otorgada a cada inadecuación es orientativa, para saber qué grado tiene cada una (traducción directa/traducción inversa).

- Según cada encargo de traducción, la baremación cambiará o se aplicará una valoración general de la traducción.

- El estilo se señala, pero no puntúa.

\section{INADECUACIONES QUE AFECTAN A LA COMPRENSIÓN DEL TEXTO ORIGINAL}

1.1. Contrasentido

1.2. Falso sentido

1.3. Sin sentido

1.4. Adición innecesaria de información (AD)

1.5. Supresión innecesaria de información

1.6. Referencia cultural mal solucionada

1.7. No mismo sentido

1.8. Inadecuación de variación lingüística

\section{$(\mathrm{NMS})^{17}$}

$(\mathrm{CS})^{14}$
$(\mathrm{FS})^{15}$

$-0,75 /-1$

$-0,25 /-1$

(SUP)

(CULT)

$7 \quad-0,25 /-1$

$(\mathrm{IVL})^{18} \quad-0,25 /-1$

\footnotetext{
${ }^{14}$ Contrasentido: atribuir a una palabra o a un grupo de palabras un sentido erróneo o, de modo más general, traicionar el pensamiento del autor del texto original.

${ }^{15}$ Falso sentido: mala apreciación del sentido de una palabra o de un enunciado en un contexto dado, sin llegar a causar contrasentido o sin sentido.

${ }^{16}$ Sin sentido: dar a un segmento del texto original una formulación en la lengua de traducción totalmente desprovista de sentido o absurda.

${ }^{17}$ No mismo sentido: apreciación inadecuada de un matiz de un elemento del texto original (exageración/reducción, concreto/abstracto, ambigüedad, falta de precisión...).

18 Tono, dialectos, idiolectos...
} 


\title{
2. INADECUACIONES QUE AFECTAN A LA EXPRESIÓN EN LA LENGUA DE TRADUCCIÓN
}

$\begin{array}{lll}\text { 2.1. Ortografía y puntuación } & \text { (OP) } & -1 /-0,25 \\ \text { 2.2. Gramática } & \text { (GR) } & -1 /-1 \\ \text { 2.3. Léxico } & \text { (LEX) } & -1 /-1 \\ \text { 2.4. Textual } & (\text { TEXT })^{19} & -1 /-0,5 \\ \text { 2.5. Redacción } & (\mathrm{R})^{20} & -1 /-0,5\end{array}$

3. INADECUACIONES PRAGMÁTICAS(PR $)^{21}-1 /-1$

\section{ACIERTOS}

4.1. Buena equivalencia

4.2. Muy buena equivalencia

(B) $\quad+0,75$

5. ESTILO

(MB) $\quad+1$

\author{
(EST)
}

¡EN CUALQUIER CASO, UNA FALTA ORTOGRÁFICA GRAVE EN ESPAÑOL SUPONDRÁ EL SUSPENSO AUTOMÁTICO!

\subsection{Normas y criterios de evaluación}

1. Pruebas escritas parciales individuales

- Las pruebas parciales serán unas pruebas escritas que consistirán cada una en la traducción (jurada) de uno o varios textos o fragmentos de textos de temática jurídica y/o socioeconómica, de características similares a los realizados en clase. Además, se tendrá que responder a una serie de cuestiones relativas a los problemas de traducción encontrados en el desarrollo de la prueba y/o a cuestiones teórico-prácticas más generales tratadas en el temario de la asignatura. Para la realización de las pruebas parciales el estudiante puede utilizar todas las obras de referencia y toda la documentación que considere necesarias, tanto en papel como electrónicas. Podrá utilizar asimismo Internet. El tiempo total asignado a cada prueba no excederá de una hora y treinta minutos.

- Se realizarán dos pruebas escritas parciales de carácter estrictamente individual correspondientes a los tres bloques temáticos principales de la asignatura: traducción jurada y jurídica (40 \%) y traducción

\footnotetext{
${ }^{19}$ Coherencia, cohesión, progresión temática...

${ }^{20}$ Formulación defectuosa o poco clara, falta de riqueza expresiva, pleonasmos...

${ }^{21}$ No se respetan la finalidad de la traducción, el método elegido, el género textual y sus convenciones...
} 
socioeconómica (40 \%). Su secuenciación temporal estará establecida en el cronograma orientativo de la asignatura.

- Se valorará en cada una de ellas tanto la calidad de la traducción (proceso y producto) de acuerdo con el baremo de corrección de traducciones como la reflexión crítica y documentada sobre cuestiones adicionales acerca de la traducción de textos de temática jurídica y/o socioeconómica que se planteen.

- Para que computen todos los porcentajes, es necesario obtener una nota mínima de 4 sobre 10 en cada una de las pruebas escritas parciales individuales (traducción jurada y jurídica y traducción socioeconómica).

\section{Encargos de traducción}

- Los encargos de traducción (instrucciones y texto original) se colgarán por la profesora en el Campus Virtual con la antelación suficiente para su preparación previa a la fecha de la exposición en clase.

- Los encargos de traducción se realizarán siempre en parejas, preferiblemente pertenecientes al mismo Grupo Reducido. En cada sesión de exposición una pareja expondrá públicamente su trabajo para la revisión por parte del resto de estudiantes con supervisión de la profesora.

- Todas las parejas deberán enviar su encargo de traducción como Tarea en la sección destinada a tal efecto en el Campus Virtual de la asignatura una vez concluida su revisión, de acuerdo con la secuenciación temporal que se establecerá en el cronograma orientativo de la asignatura. El encargo será enviado solo por un miembro de la pareja.

- Se entregarán tres encargos de traducción, correspondientes cada uno de ellos a cada uno de los tres bloques temáticos principales de la asignatura: traducción jurada $(3,4 \%)$, traducción jurídica $(3,3 \%)$ y traducción socioeconómica (3,3\%). En el cronograma orientativo de la asignatura se especificarán los encargos.

- Únicamente se valorará su entrega en tiempo y forma, si bien su entrega no será obligatoria para que computen el resto de porcentajes de los componentes de evaluación de la asignatura.

- El encargo de traducción se hará en un documento Word con un nombre asignado de acuerdo con la siguiente secuencia: "Encargo1(2,3)_Apellido1Nombre1\&Apellido2Nombre2.doc(x)". Ejemplo: "Encargo1_BlancoJesus\&SanchezEsther.doc(x)".

- Su presentación es de formato libre, si bien deberá adecuarse a las normas de presentación de un trabajo académico. Ejemplo: "Hoja de estilo" del Trabajo Fin de Grado del Grado en Traducción e Interpretación de la Universidad de Málaga.

- Para la exposición en clase del encargo de traducción se podrán utilizar el formato y los medios que se consideren oportunos. 
- La valoración en clase de los encargos de traducción obedecerá a los siguientes criterios:

\begin{tabular}{|c|c|c|}
\hline Componentes & Criterios de evaluación & Puntuación \\
\hline $\begin{array}{l}\text { Análisis } \\
\text { introductorio }\end{array}$ & $\begin{array}{l}\text {-Factores extratextuales } \\
\text {-Factores intratextuales } \\
\text {-Relación con el encargo de } \\
\text { traducción }\end{array}$ & $1,5 / 10$ \\
\hline Presupuesto & $\begin{array}{l}\text {-Presupuesto adecuado al contexto } \\
\text { profesional }\end{array}$ & $1 / 10$ \\
\hline Texto original & -Presentación adecuada & $0,5 / 10$ \\
\hline $\begin{array}{l}\text { Traducción } \\
\text { (con control } \\
\text { de cambios: } \\
\text { versión original } \\
\text { y traducción } \\
\quad \text { final) }\end{array}$ & $\begin{array}{l}\text {-Errores/aciertos de traducción según } \\
\text { el "Baremo de corrección de } \\
\text { traducciones" } \\
\text {-Justificación de la traducción } \\
\text { (dificultades encontradas y } \\
\text { resolución) } \\
\text {-Expresión correcta en español y en } \\
\text { inglés }\end{array}$ & $5 / 10$ \\
\hline $\begin{array}{l}\text { Documentación } \\
\text { comentada }\end{array}$ & 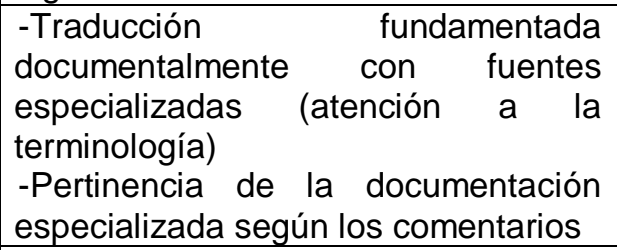 & $1 / 10$ \\
\hline Factura & $\begin{array}{l}\text {-Factura adecuada al contexto } \\
\text { profesional }\end{array}$ & $1 / 10$ \\
\hline Presentación & $\begin{array}{l}\text {-Expresión oral/escrita correcta en } \\
\text { español y en inglés } \\
\text {-Participación de todos los miembros } \\
\text { de la pareja (pero solo una versión } \\
\text { final) } \\
\text {-Presentación con medios adecuados } \\
\text { (PowerPoint, Prezi, Word, pizarra...) }\end{array}$ & $-0,25$ \\
\hline
\end{tabular}

\section{Glosarios electrónicos}

- Existirán dos glosarios electrónicos disponibles para su elaboración por parte de los estudiantes en el Campus Virtual de la asignatura: uno correspondiente a términos del ámbito jurídico inglés-español-inglés y otro correspondiente a términos del ámbito socioeconómico inglés-españolinglés. 
- Los glosarios de traducción se realizarán siempre en grupos de trabajo, cuya composición se especificará en el foro correspondiente en un único mensaje de un miembro del grupo.

- Cada grupo de trabajo deberá elegir un término del texto original de cada encargo de traducción realizado y revisado en clase y elaborar una ficha terminológica del mismo de acuerdo con el "Modelo de ficha terminológica" expuesto en la asignatura.

- Las fichas deberán ser colgadas en el glosario electrónico pertinente con la fecha límite que se establecerá en el cronograma orientativo de la asignatura. La ficha será colgada solo por un miembro del grupo. La ficha se insertará en el glosario electrónico; no se adjuntará como documento independiente.

- No se podrán repetir términos.

- Su adecuada realización se valorará en el porcentaje asignado al glosario terminológico (5\%), si bien su entrega no será obligatoria para que computen el resto de porcentajes de los componentes de evaluación de la asignatura.

\section{Foros de debate}

- Existirán dos foros de debate disponibles para su uso por parte de los estudiantes en el Campus Virtual de la asignatura: uno correspondiente a la formación continua en el campo de la traducción de textos de temática jurídica y/o socioeconómica y otro correspondiente a la profesión del traductor especializado en la traducción de textos de temática jurídica y/o socioeconómica.

- Estos foros no tienen la finalidad de intercambio de documentación para la preparación de las pruebas escritas o para la realización de las actividades de clase/Campus Virtual.

- La participación en los foros de debate será siempre individual.

- Cada estudiante podrá participar con un máximo de tres entradas por foro ( 3 entradas equivalen a una puntuación de 10/10), entre las que se incluyen las respuestas a entradas anteriores en diferentes hilos de conversación.

- La participación en los foros estará limitada temporalmente según el cronograma orientativo de la asignatura.

- Su adecuada realización se valorará en el porcentaje asignado a participación en foros (5\%), si bien su entrega no será obligatoria para que computen el resto de porcentajes de los componentes de evaluación de la asignatura.

La participación individual y grupal en tareas de clase y en la exposición de los encargos de traducción será tenida en cuenta en la 
evaluación final de la asignatura como parte de la evaluación formativa del estudiante.

\section{REFERENCIAS BIBLIOGRÁFICAS}

Calvo Encinas, Elisa, Análisis curricular de los estudios de Traducción e Interpretación en España: Perspectiva del estudiantado. Universidad de Granada. Tesis Doctoral inédita, 2009. Disponible en línea en: http://0-hera.ugr.es.adrastea.ugr.es/tesisugr/1852574x.pdf [Fecha de consulta: 26 de febrero de 2016].

DELISLE, Jean, L'analyse du discours comme méthode de traduction: Initiation à la traduction française de textes pragmatiques anglais, théorie et pratique. Universidad de Ottawa, 1980.

-, La traduction raisonnée. Manuel d'initiation à la traduction professsionnelle de l'anglais vers le français. Universidad de Ottawa, 1993.

Hatim, Basil; MASON, lan, Discourse and the Translator. Citado por la traducción española de Salvador Peña: Teoría de la traducción. Una aproximación al discurso. Barcelona: Ariel, 1995.

—, The Translator as Communicator. London: Routledge, 1997.

HURTADO AlBIR, Amparo (dir.), Enseñar a traducir. Metodología en la formación de traductores e intérpretes. Madrid: Edelsa, 1999.

KIRALY, Donald, Pathways to Translation. Pedagogy and Process. Kent State University Press, 1995.

-, A Social Constructivist Approach to Translator Education. Manchester: St. Jerome, 2000.

-, "Towards A View of Translator Competence as an Emergent Phenomenon: Thinking Outside the Box(es) in Translator Education". En: Kiraly, Donald; Silvia Hansen-Schirra \& Karin Maksymski (eds.), New Prospects and Perspectives for Educating Language Mediators. Tubinga: Narr Verlag, 2013, pp. 197-224.

LI, Defeng, "Teaching business translation. A task-based approach". En: The Interpreter and Translator Trainer 7, 1, 2013, pp. 1-26.

MuÑoz RAYA, Eva (coord.), Libro Blanco. Título de Grado en Traducción e Interpretación. Agencia Nacional de Evaluación de la Calidad y Acreditación y Universidad de Granada, 2004. Disponible en línea en:http://www.aneca.es/media/150288/libroblanco_traduc_def.pdf [Fecha de consulta: 26 de febrero de 2016].

NeUberT, Albrechtm, "Text-bound translation teaching", En: Wills, W. \& Thome, G. (eds.), Die Theoric des übersetzens und ihr Aufschlumwert für die Übersetzungs - und Dolmetschdidatick. Tubinga: Narr Verlag, 1994, pp. 61-70. 
NeUBERT, Albrecht; SHREVE, Gregory, Translation as Text. Kent State University Press, 1992.

NoRD, Christiane, Text Analysis in Translation: Theory, Methodology and Didactic Application of a Model for Translation-Oriented Text Analysis. Amsterdam: Rodopi, 1991.

-, Translating as a Purposeful Activity. Manchester: St. Jerome, 1997.

-, "Training functional translators". En: Tennent, Martha (ed.), Training for the New Millenium. Pedagogies for translation and interpreting. Ámsterdam: John Benjamins, 2005, pp. 209-223.

SocorRo TRUJILLO, Karina, "La enseñanza de la traducción directa de la correspondencia comercial inglés-español: hacia una competencia textual del comercio internacional”. En: Sendebar, 23, 2013, pp. 301320. Disponible en línea en:

http://revistaseug.ugr.es/index.php/sendebar/article/view/40/40.

[Fecha de consulta: 26 de febrero de 2016].

VV.AA., Memoria de Verificación del Título de Graduado/a en Traducción e Interpretación por la Universidad de Málaga, 2008. Disponible en línea en:

http://www.uma.es/ordenac/docs/OfertaPlanesGR/PGRTraduccionln terpretacion.pdf [Fecha de consulta: 26 de febrero de 2016].

VV.AA., Plan de Ordenación Docente de la Universidad de Málaga. Curso académico 2015-2016, 2015. Disponible en línea en: http://www.uma.es/fest/noticias/plan-de-ordenacion-docente-pod-delcurso-20152016/ [Fecha de consulta: 26 de febrero de 2016].

Vermeer, Hans J., "Didactics of Translation". En: Baker, M. (ed.), Routledge Encyclopedia of Translation Studies. London: Routledge, 1998, pp. 60-63. 